Supporting Information

\title{
Nanomechanical behavior of high gas barrier multilayer thin films
}

Mohammad Humood, ${ }^{1}$ Shahla Chowdhury, ${ }^{1}$ Yixuan Song, ${ }^{2}$ Ping Tzeng, ${ }^{1}$ Jaime C. Grunlan* ${ }^{1,} 2$ Andreas A. Polycarpou**,1

${ }^{1}$ Department of Mechanical Engineering, Texas A\&M University, College Station, TX 778433123, United States

2 Department of Materials Science and Engineering, Texas A\&M University, College Station, Texas 77843-3003, United States

*To whom correspondence should be addressed, phone: 979-845-3027, email: jgrunlan@tamu.edu

** To whom correspondence should be addressed, phone: 979-458-4061, email: aploycarpou@tamu.edu 


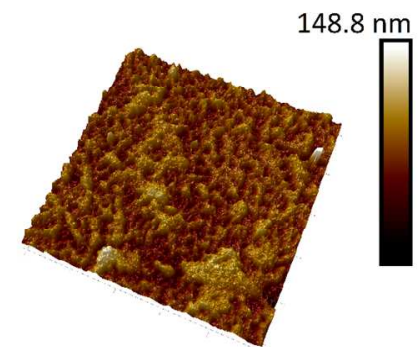

$(\mathrm{PEI} / \mathrm{PAA} / \mathrm{PEI} / \mathrm{GO})_{30}$

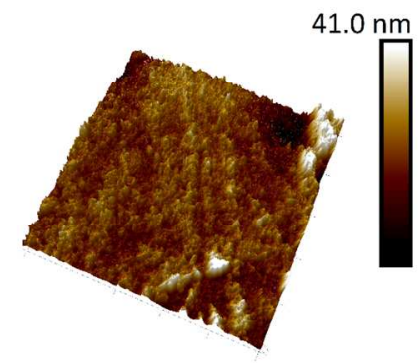

$(\mathrm{PEI} / \mathrm{MMT})_{50}$

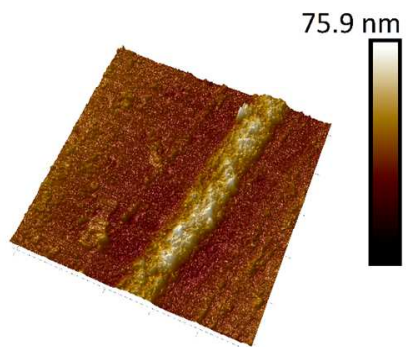

$(\mathrm{PEI} / \mathrm{PAA} / \mathrm{PEI} / \mathrm{MMT})_{10}$

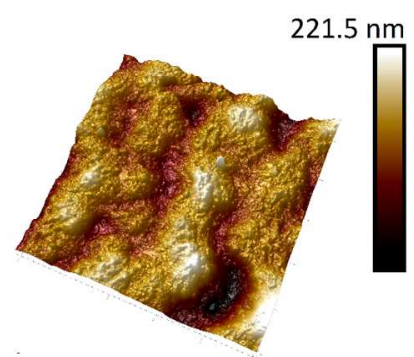

$(\mathrm{PEI} / \mathrm{PAA})_{8}$

Figure. S1. Atomic Force Microscopy topography images $(5 \times 5 \mu \mathrm{m})$ of the multilayer thin films. Subscripts refer to the number of bilayers or quadlayers deposited. 

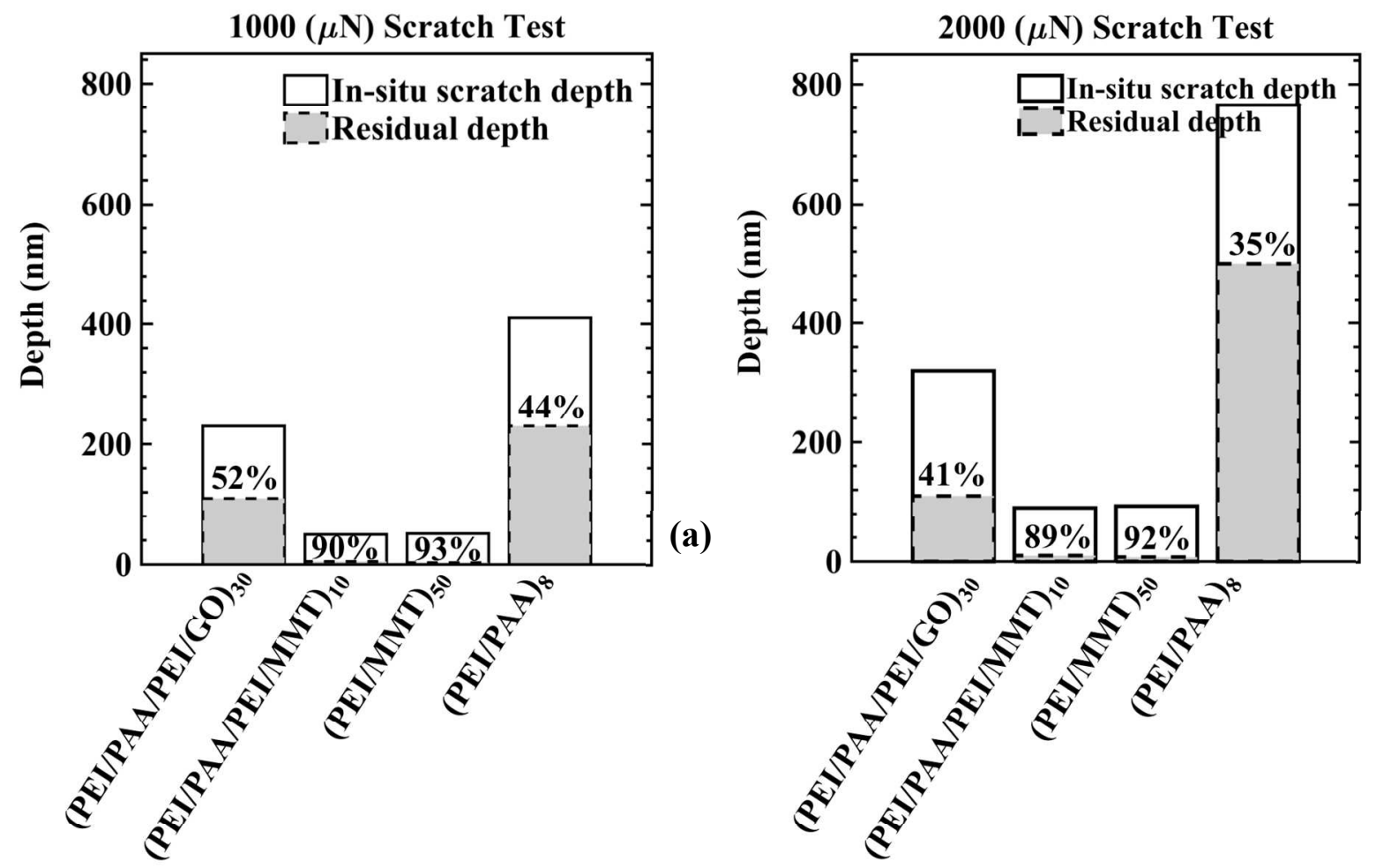

(b)

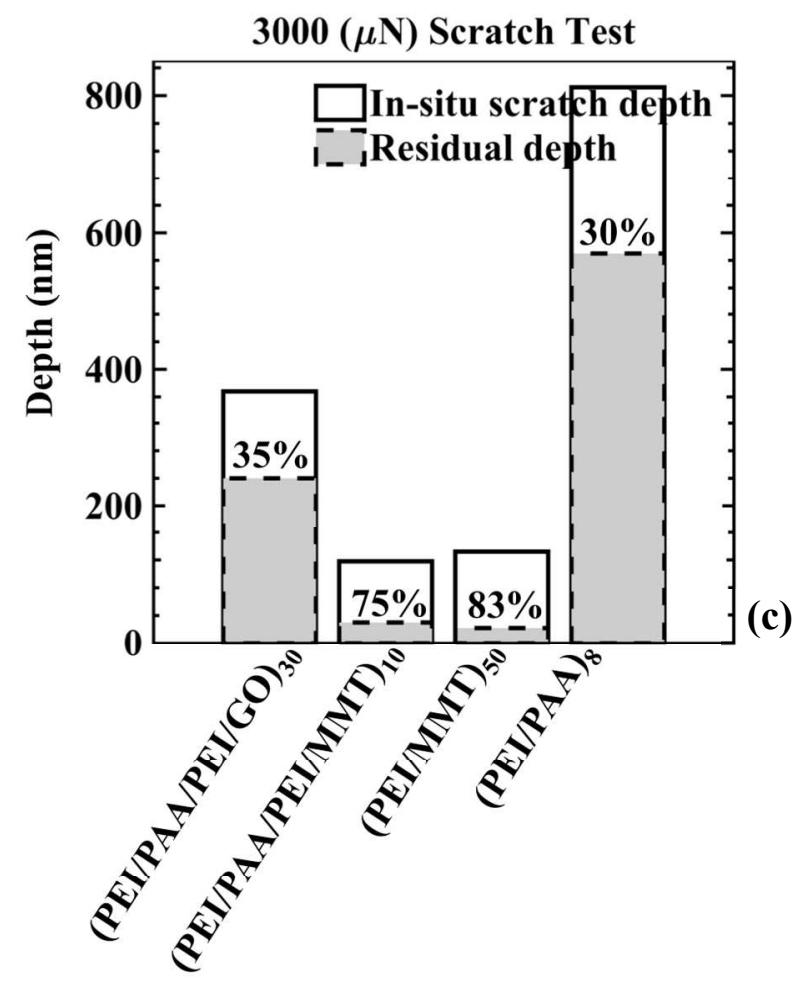

Figure S2. In-situ scratch depth and residual scratch depths of multilayer thin films scratched with high loads, (a) 1, (b) 2 and (c) $3 \mathrm{mN}$. 